\title{
Investigation on the grain boundary strengthening effect of a nickel-based superalloy
}

\author{
DongFang $\mathrm{Shi}^{1}$, Zhenjun Zhang ${ }^{2}$, Jinhai $\mathrm{Hu}^{3}$, and Zhefeng Zhang ${ }^{2}$ \\ ${ }^{1}$ Institute of Metal Research Chinese Academy of Sciences \\ ${ }^{2}$ Institute of Metal Research, Chinese Academy of Sciences \\ ${ }^{3}$ Northeastern University
}

August 26, 2020

\begin{abstract}
The grain boundary strengthening effect (GBSE) was investigated for nickel-based superalloy bicrystals with various misorientations under different temperatures and loading directions. The results show that the GBSE is enhanced with the increase of misorientation and insensitive to the temperature. Besides, the loading direction relative to GB also has strong effect on GBSE. On the other hand, the GBSE is often accompanied by GB cracking. The trend of GB cracking is heightened with the increase of misorientation and temperature. However, the trend of GB cracking is reduced strongly when the loading direction transforms from parallel direction to vertical direction.
\end{abstract}

\section{Hosted file}

Cover Letter.doc available at https://authorea.com/users/354111/articles/477758investigation-on-the-grain-boundary-strengthening-effect-of-a-nickel-based-superalloy

\section{Hosted file}

Investigation on the grain boundary strengthening effect.doc available at https://authorea. com/users/354111/articles/477758-investigation-on-the-grain-boundary-strengtheningeffect-of-a-nickel-based-superalloy

\section{Hosted file}

Declaration of interest statement.doc available at https://authorea.com/users/354111/ articles/477758-investigation-on-the-grain-boundary-strengthening-effect-of-a-nickelbased-superalloy 